\title{
Dosing of oral penicillins in children: is big child=half an adult, small child=half a big child, baby=half a small child still the best we can do?
}

The improving Children's Antibiotic Prescribing UK Research Network thinks it's time to abandon this historical rule of thumb

Umar Ahmed pharmacist ${ }^{12}$, Nikos Spyridis consultant in paediatric infectious diseases ${ }^{34}$, lan C K Wong professor of paediatric medicines research ${ }^{15}$, Mike Sharland professor of paediatric infectious diseases $^{3}$, Paul F Long senior lecturer in pharmacognosy ${ }^{16}$, on behalf of the improving Children's Antibiotic Prescribing UK Research Network (iCAP)

\footnotetext{
${ }^{1}$ Centre for Paediatric Pharmacy Research, School of Pharmacy, University of London, London WC1H 9JP, UK; ${ }^{2}$ Boots The Chemist, London, UK ; ${ }^{3}$ Paediatric Infectious Diseases Unit, St George's Hospital, London, UK ; ${ }^{4} \mathrm{P}$ and A Kyriakou Children's Hospital, University of Athens, Athens, Greece; ${ }^{5}$ Department of Pharmacology and Pharmacy, Li Ka Shing Faculty of Medicine, University of Hong Kong, Hong Kong; ${ }^{6}$ Institute of Pharmaceutical Science and Department of Chemistry, King's College London, London, UK
}

The penicillins have been the most important antibiotics used in children for over 50 years. As well as combating the rapid emergence of penicillinase producing bacteria, the development of penicillin derivatives in the 1950s and 1960s allowed oral dosing, removing the need for painful intramuscular injections. Penicillin V, flucloxacillin, and amoxicillin account for nearly 4.5 million of the 6 million prescriptions for oral antibiotics given to children in England each year. ${ }^{1}$

Despite their wide use over many decades, guidance on the correct dose of oral penicillins for children remains confusing. For example, the 2011 summary of product characteristics for Amoxil paediatric suspension in children weighing $<40 \mathrm{~kg}$ is $40-90 \mathrm{mg} / \mathrm{kg} /$ day for all indications, ${ }^{2}$ whereas recommendations for amoxicillin, penicillin V, and flucloxacillin in the British National Formulary for Children are mostly based on age bands, although weight bands or weight based calculations $(\mathrm{mg} / \mathrm{kg})$ are given for some indications. The widely used doses of 62.5 $\mathrm{mg}$ or $125 \mathrm{mg}$ are fractions of the adult dose recommended in the British National Formulary $(B N F)$ and are still based on the original dosing principle of a big child=half an adult, small child=half a big child, baby=half a small child $\downarrow \downarrow \downarrow$.

\section{Limited evidence for dosing regimens}

To understand the origins of the age band dosing schedule, we conducted a historical review of the literature and earlier UK prescribing formularies. This comprised an electronic search of PubMed (using a combination of terms including the antibiotic name, child/paediatric, dose, clinical trial, review, pharmacokinetic) and the summary of product characteristics, a manual search through the archives of the Royal Pharmaceutical Society of Great Britain and British Medical Association, and requests for dosing information submitted under the freedom of information acts to the UK Medicines and Healthcare Products Regulatory Agency and the US Food and Drug Administration. Electronic copies of all the articles recovered from our search are available on request.

The first published studies on oral dosing in children were from 1946 and used penicillin G. ${ }^{34}$ These and subsequent studies all used child weight to determine dosage (units/lb body weight). ${ }^{5-7}$ The results showed that the success of oral administration, particularly in children over 1 year old, was essentially a matter of trial and error because the variation in absorption of the drug was so unpredictable. If $1 \mathrm{mg}$ of penicillin equalled 1667 units, ${ }^{8}$ the highest dose of penicillin $\mathrm{G}$ that gave consistent bacteriostatic serum levels in these studies was equivalent to about $60 \mathrm{mg}$ every 3 hours, but only in children up to 1 year old. This meant that oral penicillin $G$ was not practical for children older than 1 year with severe illness, and subsequent studies focused on attempts to prolong the therapeutic action of a single injection of penicillin G. Two studies suggested that doses intermediate between those used in infants and adults should be clinically effective in children..$^{9} 10$

By 1958 penicillin V had become available and was clearly the oral antibiotic of choice. A contemporary survey published in 
the $B M J$ showed that many UK general practitioners had adopted an age banding dosing system, with children aged under 5 years old receiving $60 \mathrm{mg}$ every 3 hours and older children receiving what was then the recommended adult dose of $125 \mathrm{mg}$ every 3 hours. ${ }^{11}$ Prescribing based on age, albeit using a wider range of age bands, had first been suggested in 1953 at an antibiotic conference held in Vienna. ${ }^{12}$ Based on the results of oral dosing studies conducted using the scheme for penicillin $G$ described at the conference, ${ }^{13}$ a general recommendation to use age banding for all antibiotics in children, irrespective of the type of penicillin or disease indication, was published in the $B M J$ in 1963. ${ }^{14}$ Critically, these recommendations have remained unchallenged and unchanged to this day.

\section{Many children may be underdosed}

Recommended dosing regimens for penicillin V (fig $1 \Downarrow$ ) in children first appeared in the 1963-66 edition of the BNF and have not been changed since. The $B N F$ recommends halving the single dose between successive age bands starting from the maximum adult dose of $1000 \mathrm{mg}$ as follows: $12-18$ years, 500 $\mathrm{mg}$; 6-12 years, $250 \mathrm{mg}$; $1-5$ years, $125 \mathrm{mg}$; <1 year, $62.5 \mathrm{mg}$. The same halving of single doses between age bands from the adult dose has also remained unchanged for flucloxacillin, which first appeared in the 1974-76 edition of the $B N F$, and for amoxicillin, which was first recommended for use in children in the 1976-78 edition. Adult penicillin doses have increased substantially over the years, presumably in response to concerns around increasing antibiotic resistance, but there has been no parallel increase in children's dosing (fig $1 \Downarrow$ ).

The 1963 BNF included average weight of a child with the age band dosing information: $10 \mathrm{~kg}$ (birth to 1 year), $13 \mathrm{~kg}$ ( 2 years), $18 \mathrm{~kg}$ (5 years) and $30 \mathrm{~kg}$ (10 years). But data used to compile the Health Survey for England 2009 gave the average weights of 5 and 10 year old children as $21 \mathrm{~kg}$ and $37 \mathrm{~kg}$, respectively, significantly higher than the 1963 figures. ${ }^{15}$ This suggests that the $\mathrm{mg} / \mathrm{kg}$ doses may be even lower than those set in 1963 .

We therefore analysed the actual dose that would be received today as both the $\mathrm{mg} / \mathrm{kg} / \mathrm{dose}$ and $\mathrm{mg} / \mathrm{kg} / \mathrm{day}$ for the oral penicillins based on the age bands recommended in the 2010-11 $B N F$ for Children and the current weights of children based on the 2009 Health Survey for England data (fig $2 \Downarrow$ ). The main problem with age and weight bands is that at older age-weight ranges, substantially lower doses are always recommended. These doses seem strikingly low-for example, a 10 year old child weighing around $40 \mathrm{~kg}$ and receiving amoxicillin $250 \mathrm{mg}$ three times a day will receive only around $18 \mathrm{mg} / \mathrm{kg} / \mathrm{day}$, much lower than the $40-90 \mathrm{mg} / \mathrm{kg} /$ day recommended in the summary of product characteristics for Amoxil.

\section{Time for an update}

The evidence base for many older medicines for children is limited, but we were surprised at the lack of recent evidence to support the BNF's current dosing recommendations for such commonly used drugs as the oral penicillins. The same dosing recommendations seem to have been reused every year for the past 50 years (fig $1 \Downarrow$ ). In the 1940 s and early 1950 s dosing was based on weight, but age bands were introduced from the late 1950s alongside $2.5 \mathrm{ml}$ and $5 \mathrm{ml}$ spoons, which standardised practice and reduced the risk of medication error. The UK's age band dosing recommendations are much lower than the doses recommended by the American Academy of Pediatrics, ${ }^{16}$ for example, but does this actually matter, or cause any harm?
Low dosing will lead to subtherapeutic concentrations at the relevant target organ (especially the middle ear), potentially driving antimicrobial resistance, ${ }^{17} 18$ with consequences for both the individual and the community. ${ }^{19}$ Underdosing may result in the need for retreatment and increases the risk of severe complications. All the published risk-benefit analyses on the therapeutic balance of antibiotic prescribing for upper respiratory tract infections assume adequate antibiotic dosing. ${ }^{20}$ This is a real concern because clinically inadequate dosing would increase the number needed to treat to prevent any severe complications. Studies of paediatric antiretroviral dosing noted that complex schedules using weight bands often led to clinically important underdosing since changes in growth and obesity had not been accounted for. ${ }^{21}$ This work led to substantial changes in the dosing recommendations for children receiving antiretrovirals and to standardised treatment guidelines across Europe. ${ }^{22} \mathrm{~A}$ similar programme of work is now required for oral penicillins. Not only do we need to determine the effective doses for children of all ages and weights but we also need to establish more clearly which children really need antibiotics in the era of pneumococcal conjugate (PCV 13), Haemophilus influenzae $\mathrm{B}$, and meningitis $\mathrm{C}$ vaccines. The rates of prescribing of oral penicillins for children are now rising again in England (primary care trust prescribing data, 2010). Many of the 5 million children in England who receive oral penicillins each year may not need them, but those who do should receive them in an effective dose.

We thank Hywell Dinsdale and Louisa J Ells of the National Obesity Observatory for providing the data on child weights. We also thank the staff at the libraries of the Royal Pharmaceutical Society of Great Britain and BMA for help and Inderjit Thakhar for data collection.

Contributors and sources: NS, MS, PFL, and ICKW conceived the idea of the study. UA collected the data. MS and PFL analysed the data. All authors interpreted the data and had full access to the study data and can take responsibility for the integrity of the data and the accuracy of the data analysis. MS and PFL drafted the manuscript. All authors revised and approved the final manuscript. PFL is the guarantor.

Competing interests: All authors have completed the unified competing interest form at www.icmje.org/coi_disclosure.pdf (available on request from the corresponding author) and declare no financial support for the submitted work from anyone other than their employer; ICKW, MS, and PFL receive non-personal research funding from Wyeth Vaccines; they have no non-financial interests that may be relevant to the submitted work.

Provenance and peer review: Not commissioned; externally peer reviewed.

1 Thompson PL, Spyridis N, Sharland M, Gilbert RE, Saxena S, Long PF, et al. Changes in clinical indications for community antibiotic prescribing for children in the UK from 1996 to 2006: will the new NICE prescribing guidance on upper respiratory tract infections just be ignored? Arch Dis Child 2009;94:337-40.

2 Electronic Medicines Compendium. Summary of product characteristics: Amoxil paediatric suspension. 2011. www.medicines.org.uk/EMC/medicine/12637/SPC/ Amoxil+Paediatric+Suspension.

3 Buchnan JL. Penicillin in infancy and childhood. Lancet 1946;248:560-2.

4 Henderson JL, McAdam IWJ. Oral administration of penicillin to infants. Lancet 1946;247:922-5.

5 Hoffman WS, Hofer JW, Gordon $\mathrm{H}$. The treatment of acute respiratory infections in children with orally administered, unbuffered penicillin solutions. J Pediatr 1948;32:1-9.

6 Moseley JH. The place of oral penicillin in paediatrics. Arch Dis Child 1948;23:93-7.

7 Suchett-Kaye AI, Latter RB. Oral penicillin in young children. BMJ 1947;ii:953-4.

8 Knudsen LF, Randall WA. Penicillin assay and its control chart analysis. J Bacteriol 1945;50:187-200.

9 Young BA. Medical aspects of penicillin treatment. BMJ 1947;viii:290-3.

10 Emery JL, Rose LM, Stewart SM, Wayne EJ. The use in children of procaine penicillin with aluminium monostearate. $B M J 1949 ;$;:1110-2.

11 Wheatley D. Oral penicillin in general practice. BMJ 1958;2:907-9.

12 Hausmann E, Zischinsky H. Experience with ospen, a new oral penicillin therapy, in children. Wien Med Wochenschr 1953;103:725-7.

13 Spitzy, KH. Oral penicillin therapy. Wien Klin Wochenschr 1955;67:212-3.

14 Anon. Today's drug: paediatric prescribing (contd). BMJ 1963;ii:1577-8. 
15 NMH Information Centre. Health survey for England 2009. Children trends table. www.ic. nhs.uk/statistics-and-data-collections/health-and-lifestyles-related-surveys/health-surveyfor-england/health-survey-for-england--2009-trend-tables.

16 American Academy of Pediatrics Subcommittee on management of acute otitis media. Pediatrics 2004;113:1451-65.

17 Chung A, Perera R, Brueggemann AB, Elamin AE, Harnden A, Mayon-White R, et al. Effect of antibiotic prescribing on antibiotic resistance in individual children in primary care: prospective cohort study. BMJ 2007:335:429-34.

18 Vergison A, Dagan R, Arguedas A, Bonhoeffer J, Cohen R, Dhooge I, et al. Otitis media and its consequences: beyond the earache. Lancet Infect Dis 2010;10:195-203.

19 Costelloe C, Metcalfe C, Lovering A, Mant D, Hay AD. Effect of antibiotic prescribing in primary care on antimicrobial resistance in individual patients: a systematic review and meta-analysis. BMJ 2010;340:c2096.
20 Keith T, Saxena S, Murray J, Sharland M. Risk-benefit analysis of restricting antimicrobial prescribing in children: what do we really know? Curr Opin Infect Dis 2010;23:242-8.

21 Menson EN, Walker AS, Sharland M, Wells C, Tudor-Williams G, Riordan FAI, et al. Underdosing of antiretrovirals in UK and Irish children with HIV as an example of problems in prescribing medicines to children, 1997-2005: cohort study. BMJ 2006;332:1183-7.

22 PENTA 2009 guidelines for the use of antiretroviral therapy in paediatric HIV-1 infection. HIV Med 2009;10:591-613.

Cite this as: BMJ 2011;343:d7803

๑) BMJ Publishing Group Ltd 2011 
BMJ 2011;343:d7803 dol: 10.1136/bmj.d7803 (Published 15 December 2011)

Page 4 of 6

FEATURE

Figures
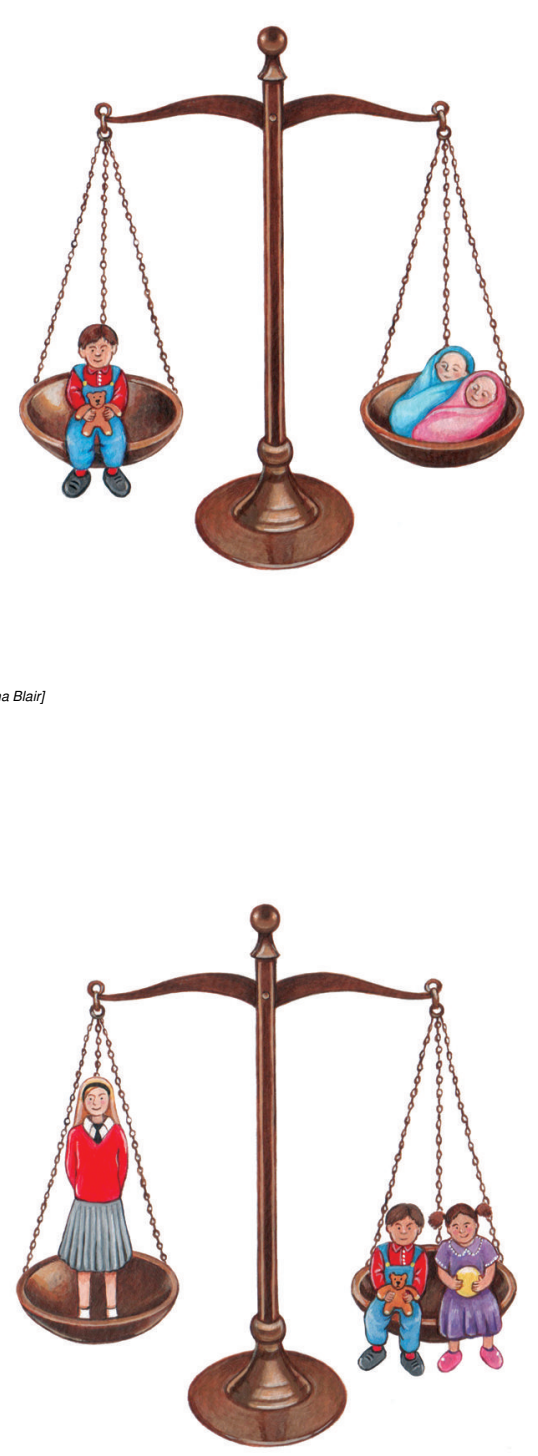

[Image: Fiona Blair]

For personal use only: See rights and reprints http://www.bmj.com/permissions

Subscribe: http://www.bmj.com/subscribe 


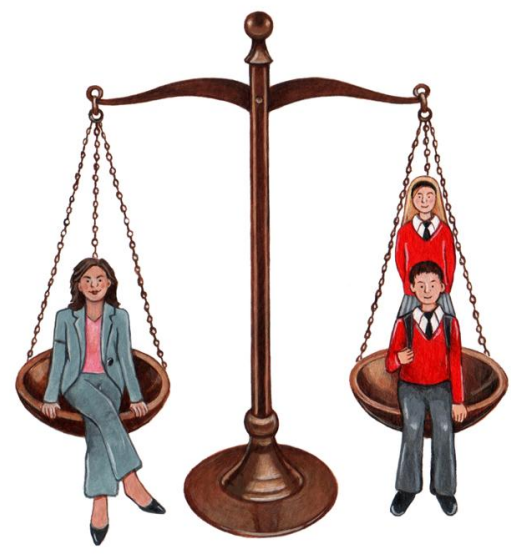

[Image: Fiona Blair]

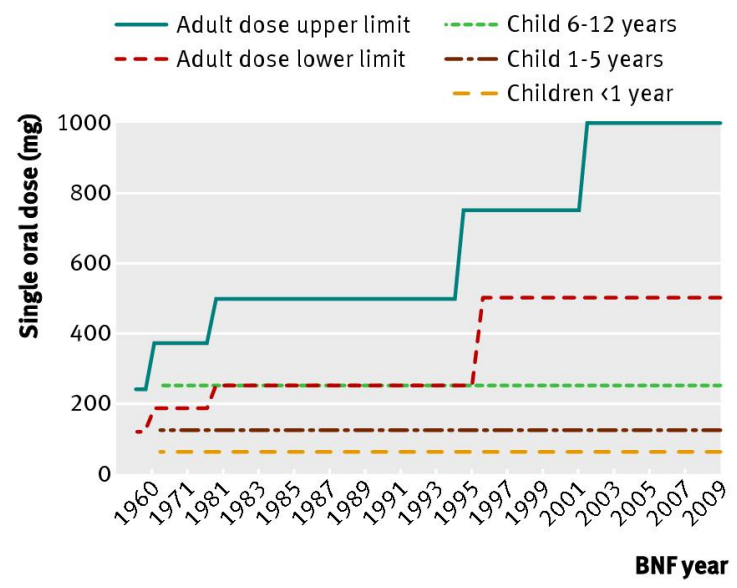

Fig 1 Changes in the single oral dose of penicillin $V$ for children and adults 
Penicillin V

- - Flucloxacillin lower limit

---- Flucloxacillin upper limit

--- Amoxicillin

- - Lowest recommended dose of Amoxil
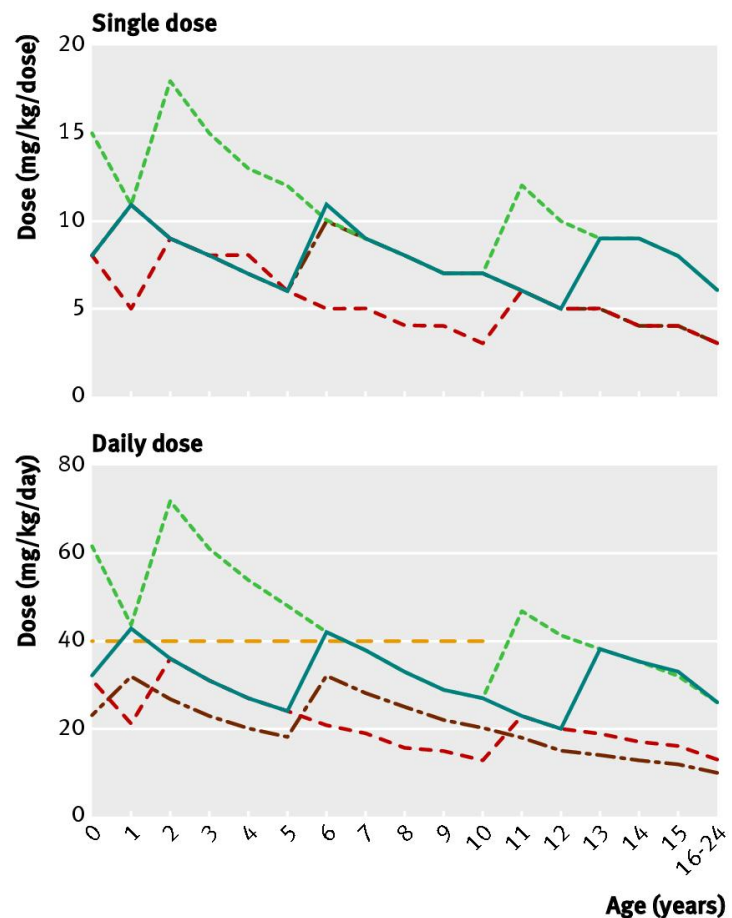

Fig 2 Actual dose of oral penicillins received as both $\mathrm{mg} / \mathrm{kg} / \mathrm{dose}$ (top) and $\mathrm{mg} / \mathrm{kg} /$ day (bottom) based on age bands recommended in the 2010-11 BNF for Children and current weights of children from 2009 Health Survey for England. (The lowest dose of Amoxil for children under $40 \mathrm{~kg}$ in the summary of product characteristics) 